travelling through the solid in its activated hybrid state between form I and form II.

A. R. UBBELOHDE

Department of Chemical Engineering and

Chemical Technology,

Imperial College of Science and Technology,

London, S.W.7.

1 Ebbelohde, A. R., Melting and Crystal Structure (Oxford University Press, 1965).

${ }^{2}$ Ubbelohde, A. R., Proc. Roy. Soc., 293, 291 (1966).

${ }^{3}$ Nixon, D. E., Parry, G. S., and Ubbelohde, A. R., Proc. Roy. Soc., A, 291 $324(1966)$.

4 Ubbelohde, A. R., Disc. Frarad. Soc., 5 (1950).

' Ubbelohde, A. R., J. Chim. Phys., 68, 33 (1966).

6 Ubbelohde, A. R., Z. Phys. Chem., 37, 183 (1963).

7 Ubbelohde, A. R., Nature, 210, 404 (1966).

\section{Pyrolytic Deposits of Silicon Carbide}

LAYERS and "whiskers" of silicon carbide have been made in several investigations ${ }^{1}$ by the thermal decomposition of the vapour of trichloromethylsilane $\left(\mathrm{CH}_{3} \mathrm{SiCl}_{3}\right)$. The experimental conditions used have varied widely, how. ever, and there has been little information about what controls the morphology of the silicon carbide produced by this method. In recent work it has been shown that the form of deposit obtained is determined mainly by the flux of the vapour species. Layers are formed above a critical flux, while filamentary deposits are formed below it.

Trichloromethylsilane vapour was entrained in hydrogen by bubbling the gas, at a controlled rate and at pressure close to atmospheric, through the liquid $\mathrm{CH}_{3} \mathrm{SiCl}_{3}$, the temperature of which was controlled and the vapour pressure known ${ }^{2}$. In most of the work, the vapour was decomposed by passing the gas/vapour mixture through a heated tube ( $3 \mathrm{~cm}$ internal diameter, alumina) containing thin liners of graphite materials, on which the carbide deposited.

The form of the deposit appeared in general to be insensitive to substrate (that is, liner) temperature in the range $1,200^{\circ}-1,700^{\circ} \mathrm{C}$, other conditions being constant. The nature of the substrate had some influence. The form of the deposit depended sensitively on the vapour flux, however, that is, vapour velocity $\times$ concentration, as indicated by Fig. 1, in which the velocity of the stream (cm min $^{-1}$, room temperature) is plotted against the prevailing vapour pressure of the trichloromethylsilane (proportional to concentration) as determined by the temperature at the bubbler. All the results shown were obtained at $1,450^{\circ} \mathrm{C}$, and the majority, indicated by circles, were from experiments in which liners of machined graphite (Morganite EY9) were used: open circles represent "whisker"-wool deposits and filled circles layer deposits. It can be seen that the kind of deposit changed consistently at a flux of $1,650 \pm 80\left(\mathrm{~cm} \mathrm{~min} \mathrm{~m}^{-1}\right)(\mathrm{mm}$ mercury), which corresponds to $\overline{138} \pm 7$ lusecs through the tube used $\left(5 \mathrm{~cm}^{2}\right.$ cross-sectional area, allowing for liner $)\left(\sim 1 \times 10^{18}\right.$ molecules $\left.\mathrm{cm}^{-2} \mathrm{sec}^{-1}\right)$. When the vapour flux at the inlet end of the tube exceeded the critical value only slightly, then only the upstream part of the deposit was a layer, the remainder being 'whisker'-wool, no doubt because of progressive depletion of vapour downstream; the length of layer deposit was proportional to, and could be predicted from, the amount by which the entry flux exceeded the critical value.

The square symbols in Fig. I correspond to the use of liners coated with pyrolytic carbon. Open squares represent "whisker"-wool deposits and closed ones represent layers. The length of the layer deposits suggested that the critical flux with this substrate is $<1,300\left(\mathrm{~cm} \mathrm{~min}{ }^{-1}\right)(\mathrm{mm}$ mercury).

Experiments with an arrangement having a hot-rod substrate in a "cold" chamber have provided qualitative supporting evidence for the foregoing results. Accurate assessment of flux in this system is impossible, but, when

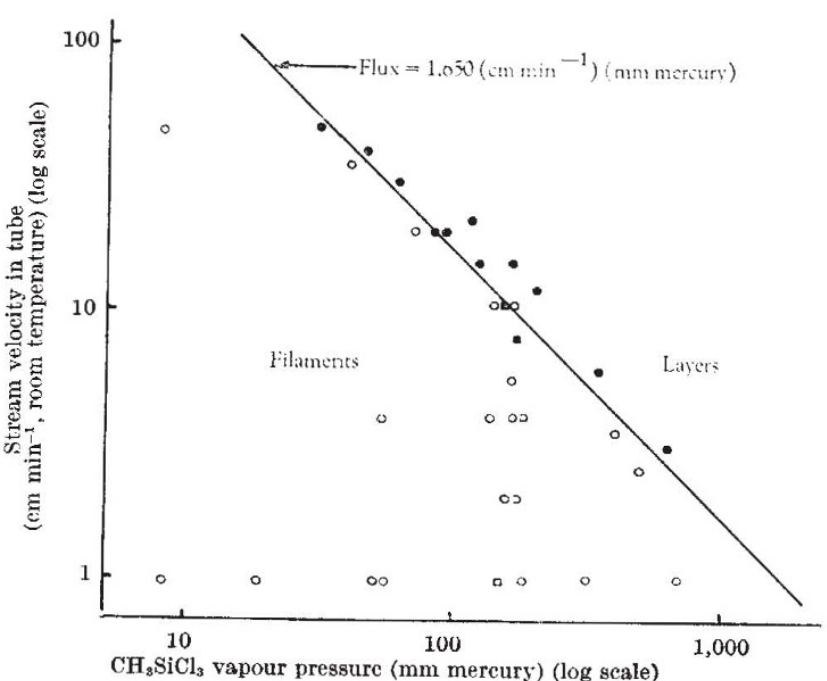

Fig. 1. Relation between deposit morphology and vapour "flux".

the flux is reduced from "high" levels giving layers, there is once again a transition to filamentary deposits.

At the lowest fluxes used in the tube apparatus, straight "whiskers" with diameter and length up to $10 \mu$ and $3 \mathrm{~cm}$. respectively, and strength up to $2.4 \times 10^{6} \mathrm{lb}$. in. ${ }^{-2}$, have been made. Whiskers of diameter less than $1 \mu$ had strength up to $4 \times 10^{6} \mathrm{lb}$. in.-2. Microscopical examination showed that some of the thicker filaments had botryoidal surface features, suggestive of spherulitic structure as in the layers (compare also filaments and layers of pyrolytic carbon). Acicular crystals of thickness $100 \mu$ and length $1 \mathrm{~mm}$ have been produced at intermediate fluxes in the chamber apparatus. Filaments of diameter up to $1 \mathrm{~mm}$ have been made by depositing the silicon carbide on to carbon fibres and on to tungsten and molybdenum wires. In all the work described the carbide deposited was predominantly of the cubic $(\beta)$ type.

The larger filaments and crystals mentioned are potentially useful for reinforcement of metallic alloys. Although their strength is less than that of the "whiskers", their size facilitates incorporation in the metallic matrix.

The work described was supported by a grant from the Ministry of Aviation.

M. J. Noone

J. P. Roberts

Houldsworth School of Applied Science,

University of Leeds.

${ }^{1}$ For example, see: Popper, $P_{\text {., }}$ and Mohyuddin, $\mathrm{Y}$., in Special Ceramics 1964, edit. by Popper, P., 45 (Academic Press, London and New York, 1965) Kirchner, H. P., and Knoli, P., J. Amer. Ceram. Soc., 46 (6), 2 Jenkins, A. C., and Chambers, G. F., Industr. Eng. Chem., 46, 2367 (1954).

\section{CHEMISTRY}

\section{Simple Spectroscopic Method for Detection of Cations}

A commercially available spectroscope, the DuoSpectranal model 80 (Fisher Scientific Co.), has been recommended for the rapid detection of more than sixty elements. This inexpensive instrument ${ }^{1}$ uses the combustion of hydrogen as an excitation source. The hydrogen is produced together with oxygen by electrolysis of an aqueous acid solution of the cations. Because the electrodes are connected to an a.c. power source, each is alternately a cathode and an anode. The hydrogen formed with the oxygen in the vicinity of the shorter electrode explodes in each current cycle.

In the standard procedure, two sets of electrodes are immersed in about $1 \mathrm{ml}$. aqueous potassium nitrate solution acidified with nitric acid. Other strong acids may be 